\title{
Characteristics of "Exemplary Teachers" and Possible Factors Affecting Their Realization According to the Perception of Principals from the Arab Sector in Israel
}

\author{
Salman Ilaiyan, Rafi' Safadi* \\ The Academic Arab College for Education in Israel, Haifa, Israel \\ Email: salman@macam.ac.il, "rafi.safadi@gmail.com \\ Received 27 December 2015; accepted 24 January 2016; published 27 January 2016 \\ Copyright (C) 2016 by authors and Scientific Research Publishing Inc. \\ This work is licensed under the Creative Commons Attribution International License (CC BY). \\ http://creativecommons.org/licenses/by/4.0/ \\ (c) (i) Open Access
}

\begin{abstract}
This study examines the characteristics of exemplary teachers and the factors that are liable to inhibit/encourage their realization according to the perception of principals from the Arab sector in Israel. Ten principals were interviewed. They considered leading educational initiatives, coping with discipline problems, subject matter mastery, and employing a variety of teaching methods to be the exemplary teacher's outstanding characteristics. Characteristics associated with ongoing professional development and relationships with colleagues, pupils, and parents were deemed less prominent. The principals did not manifest a unified stance vis-à-vis whether their schools' physical-pedagogical infrastructure encouraged or inhibited the realization of the characteristics of exemplary teaching. It was recommended that in parallel to broadening didactic and disciplinary knowledge, it would be worthwhile fostering the ability of the teachers, in particular preservice teachers and beginning teachers, to lead educational initiatives and establish interpersonal relationships, and giving them tools for coping with discipline problems.
\end{abstract}

\section{Keywords}

Exemplary Teachers, Principals, Schools' Physical-Pedagogical Infrastructure, Educational Initiatives, Discipline Problems, Organizational Climate

\footnotetext{
*Corresponding author.
}

How to cite this paper: Ilaiyan, S., \& Safadi, R. (2016). Characteristics of "Exemplary Teachers" and Possible Factors Affecting Their Realization According to the Perception of Principals from the Arab Sector in Israel. Creative Education, 7, 114-130. http://dx.doi.org/10.4236/ce.2016.71012 


\section{Introduction}

The main goal of the research described in this article was to identify the characteristics of the "exemplary teacher"1 according to the perception of principals from the Arab sector in Israel. It also aimed to scrutinize which factors the principals deem liable to inhibit/encourage the realization of these characteristics. A large body of research has investigated the characteristics of exemplary teachers, both at the school level and at the higher education level in order to identify the patterns, properties, strategies, teaching components, and classroom behaviors associated with exemplary teaching; however, it has focused neither on exemplary Arab teachers nor on how Arab principals perceive their characteristics.

Identifying how Arab school principals define an exemplary teacher is crucial since these principals embody a quasi-supreme authority in their schools; they control the system according to the school needs (Abas, 2007). Moreover, the school culture and organizational climate existing in most of the schools in the Arab sector, which are at variance with those prevailing in schools in the Western and democratic world, might affect the practices of exemplary Arab teachers and shape them differently than in the case of exemplary Western teachers. Previous research has reported that schools in the Arab sector are generally characterized by a closed organizational climate (Ilaiyan, 2000; Ilaiyan, \& Toren, 2006; Ilaiyan et al., 2007), as well as by a formal, traditional, and conservative school culture (Eilam, 2002; Tamir \& Caridin, 1993). In such a school culture, epistemological beliefs with regard to learning and teaching whereby knowledge emanates from an indisputable authority such as the teacher, are expected (Safadi \& Yerushalmi, 2009). Accordingly, investigating key features of exemplary Arab teachers as perceived by Arab school principals is of cardinal importance.

The present study is a groundbreaking study on the Arab sector, and its implications validate the need for a change in traditional perceptions. Its main goal was to reveal the characteristics of exemplary Arab teachers as reflected in the stances of the sector's principals. A secondary goal was to uncover those factors that the Arab principals perceive as liable to inhibit/encourage the realization of the exemplary teaching characteristics. Focusing the attention on such factors is also a vital goal since the education system in the Arab sector in Israel suffers from negative discrimination with regard to the allocation of resources, as well as from a serious shortage of physical and pedagogical infrastructures (Jabarin \& Agbariya, 2010; The report of the Follow-up Committee for Arab Education Affairs, 2011; Kahan \& Yelinek, 2000).

\section{Theoretical Background}

This section describes the main research skeleton and theoretical frameworks that shaped this study: (2.1) the characteristics of exemplary teachers and exemplary teaching, and (2.2) teachers' professional development.

\subsection{Characteristics of Exemplary Teachers and Exemplary Teaching}

In recent years, many studies have been conducted with the aim of identifying the characteristics of exemplary teachers at the school and higher education levels in various areas of knowledge (Cruickshank \& Haefele, 2001; Darling-Hammond, 2000; Gilat, Bar-On, Genis, Gad, \& Bachar, 2006; Hativa, 2000; Hativa, Barak, \& Simhi, 2001; Sela, 2003; Shkedi, 2000). The main notion underlying these studies posited that recognizing exemplary teachers' characteristics would facilitate the identification of the characteristics of exemplary teaching, namely, the array of patterns, strategies, skills, teaching components, and classroom behaviors associated with such teaching (Hativa, 2003a, 2003b, 2010; Sela, 2003). This array of characteristics could serve as a basis for models of successful teaching from which other teachers, in particular pre-service teachers and beginning teachers, could learn (Green, 2010; Hativa, 2003a, 2003b, 2010).

Previous studies on exemplary teachers and exemplary teaching employed diverse methods for this purpose, including the identification of the characteristics of exemplary teaching based on the nature of exemplary teachers’ teaching (Leinhardt, 1986; Lowman, 1995), “process-product research” (Brophy \& Good, 1986; Good \& Brophy, 1990), case studies focusing on a single or several exemplary teachers so as to investigate their teaching in depth (Hativa et al., 2001; Lowman, 1996), action research (Ben-Peretz, 1990), analysis of documents containing recommendations of exemplary teachers (Lowman, 1996; Sela, 2003), and research on how partners in

\footnotetext{
${ }^{1}$ The term we shall employ in this paper is "exemplary teacher", and it includes a range of terms used in previous studies in the field such as "excellent teacher", "outstanding teacher" and "ideal teacher". Accordingly, we shall employ the term "exemplary teaching” instead of the term "outstanding teaching” or "effective teaching”, which were habitually used by previous researchers.
} 
the learning-teaching process (e.g., pupils, superiors, and colleagues) perceive exemplary teachers' characteristics (Gilat et al., 2006; Sela, 2003; Young \& Shaw, 1999). The present research belongs to the latter type, and, as mentioned above, its primary goal was to examine how principals from the Arab sector in Israel perceive exemplary Arab teachers' characteristics.

Previous studies in this field have yielded a broad range of characteristics of exemplary teachers. They specified several key characteristics of exemplary teachers, among them: complete subject matter mastery (Gilat et al., 2006; Hativa \& Raviv, 1993; Holt-Reynolds, 1999; Shulman, 1997), varied teaching methods (Good \& Brophy, 1990; Tobin \& Fraser, 1987), clarity of teaching (Hativa \& Marincovich, 1995; Lowman, 1995), the ability to spark intellectual fervor among the pupils (Lowman, 1995, 1996), articulateness (Darling-Hammond, 2000), respect for the pupils (McBer, 2000), concern, caring, and sensitivity toward the pupils (Collinson, Killeavy, \& Stephenson, 1999; Lowman, 1995, 1996; Milner, Ben-Zvi, \& Hofstein, 1987), the use of humor (Lowman, 1996), and the ability to cope with unexpected classroom situations such as behavioral and attention problems (Good \& Brophy, 1990; Manross \& Templeton, 1997). Some studies even stipulate certain preconditions vis-à-vis exemplary teachers, including an academic degree in a discipline (Berliner, 1986), official teaching certification (Darling-Hammond, 2000), and teaching experience (of between five and eight years) that endows the beginning teacher with total mastery of the subject (Fetler, 1999).

The characteristics of exemplary teachers and exemplary teaching presented in the various studies were by no means identical: a characteristic that was perceived as outstanding in one study was not necessarily perceived as such in another. Thus, for instance, while there was a consensus among certain studies with regard to the existence of outstanding characteristics associated with exemplary teachers' mastery of the subject matter and pedagogical knowledge or with clarity of teaching (Gilat et al., 2006; Holt-Reynolds, 1999; Sela, 2003; Shulman, 1987), other studies did not reflect such a consensus (Manross \& Templeton, 1997).

This difference stemmed from several factors such as the dependence on the specific subject matter domain. The characteristics of the exemplary physics teacher (Sela, 2003), for instance, are not necessarily identical to those of the exemplary literature teacher (Holt-Reynolds, 1999) or of the exemplary physical education teacher (Manross \& Templeton, 1997). While Holt-Reynolds (1999) emphasizes the need for expertise in the subject matter as one of the important characteristics of the exemplary literature teacher, Manross and Templeton (1997) refer to that characteristic as less important than the way in which the exemplary physical education teacher relates to his/her pupils, for example.

The level of teaching (at the school, university, and college of education) relative to which exemplary teachers' characteristics are measured embodies an additional crucial factor. For instance, the ability to cope with discipline problems in the classroom constitutes one of the exemplary teacher's outstanding characteristics at the school level (Hines et al., 1985) but not at the higher education level, where mastery of the subject matter is more significant (Gilat et al., 2006; Hativa, 2000). The present research focuses solely on the level of school teaching.

In addition, this difference in exemplary teachers' characteristics, as revealed in the various studies, derives from the particular evaluating body: principals, colleagues, pupils, and so on. Exemplary teachers' characteristics that principals perceive as important are not necessarily perceived at the same level of importance by pupils or colleagues. For example, Sela (2003) found that alongside mastery of disciplinary knowledge and pedagogy, the pupils ascribed a great deal of importance to the teacher's attitude toward them as well as to her/his effect on their achievements and their success in exams. In contrast, principals and teachers deemed qualities such as relationships with colleagues or the ability to work in teams to be important. As mentioned previously, the present research focuses mainly on identifying exemplary teachers' characteristics according to the perception of principals from the Arab sector in Israel.

Another factor relates to the researcher himself (Hofstein \& Tamir, 1984). Studies conducted by researchers who were not affiliated with the exemplary teacher's subject matter chiefly identified general characteristics of exemplary teaching relating to the general didactic field, the teacher's personality, and her/his relationship with the pupils rather than characteristics associated with the subject matter knowledge they were teaching.

Since previous studies have revealed numerous characteristics of exemplary teachers and exemplary teaching, an attempt has been made to impose some measure of order on the topic so as to form an expanded perception of exemplary teaching. To this end, the characteristics of the exemplary teacher have been classified into a few a priori categories, sometimes called "main dimensions" of exemplary teaching (Hativa, 2003a). Various researchers have suggested a range of main dimensions (Collinson, 1996; Hativa, Barak, \& Simhi, 2001; Lowman, 
1996; Shulman, 1989). For example, Hativa (2003b) indicated two “main dimensions” characterizing exemplary teachers in higher education: 1) maintenance of effective communication, and 2) the creation of a classroom atmosphere that encourages learning.

Hativa (2003b) reached the conclusion that every exemplary teacher has her/his own profile of main dimensions and classroom practices at which s/he excels, so that there is no need for excellence in all the strategies and practices that promote "effective" teaching and "effective" learning.

In the present study, based on our research findings, we have elected to classify exemplary teachers' characteristics into main dimensions that relate to the components of teachers' professional development. In our opinion, complete mastery of these components constitutes a measure of excellence in teaching. Furthermore, we believe that this choice better reflects exemplary teachers' characteristics at the school level, on which we are focusing, than the "main dimensions" described previously. Thus, we shall describe these components and relate to previous studies in the field of teachers' professional development.

\subsection{Teachers' Professional Development}

Professional development refers to the development of the teachers' knowledge and mastery of several domains. It involves several components, the most relevant of which for the purposes of the present study are as follows:

\subsubsection{Didactic and Disciplinary Knowledge}

Didactic knowledge refers to the various components of teaching: planning, execution, and the ability to evaluate the lesson (Ziv, Silberstein, \& Tamir, 1994), the use of various teaching strategies (Chubbuck, Clift, Allard, \& Quinlan, 2001; Hertz-Lazarovich, 1984; Shulman, 1989; Vonk, 1987), the practice and acquisition of teaching skills (Sagee \& Regev, 2002; Vonk, 1987; Zuzovsky, 1998), and the preparation of learning materials and exams (Millet, 2001). It also refers to teaching procedures such as classroom management and organization (Goodlad, 1984). Classroom management includes, among other things, control of and dealing with discipline problems.

Disciplinary knowledge refers to knowledge about concepts, principles, fundamental ideas, and processes (Bloom, 1956; Bruner, 1960; Schwab, 1964), and to the curricular knowledge that necessitates familiarity with curricula and learning materials alongside the ability to utilize them (Millet, 1986, 1995; Shulman, 1987).

\subsubsection{Knowledge of the School Culture and Organization}

This refers to the teacher's knowledge of the school's background, the patterns, norms, and relationships within the school, and the relationships between the school and the parents, the community, and the official government systems. School culture is defined as a way of life that includes values, beliefs, attitudes, customs, traditions, written and unwritten rules, and rituals that are not controlled by the system (Friedman, Horowitz, \& Shliv, 1988). This way of life entails a set of expectations from colleagues, from the administration, and from the pupils (Vonk, 1995).

\subsubsection{Interpersonal Communication}

This refers to:

1) The interrelationship between teacher and pupils, which is expressed in personal contact between them, kindness, intimacy, expression of faith, mutual respect, and the teacher's support of the pupils.

2) The interrelationship between the teacher and the school staff, which includes the teacher's relationship with the principal, her/his colleagues, and the parents. The teacher's relationship with the principal has been discussed in the research literature (Amir \& Tamir, 1992; Erlich, 1992; Friedman, 2002; Talmor, Nabal-Heller, \& Erlich, 1996; Toren \& Ilaiyan, 2008). Many beginning teachers consider the principal to be the school's most important figure. They expect to receive support and guidance from her/him, as well as to enjoy open communication with her/him (Toren \& Ilaiyan, 2008). In contrast, many beginning teachers report difficulties in establishing interrelationships with their colleagues (Brock \& Grady, 1997; Toren \& Ilaiyan, 2008). As regards the relationship with the parents, many studies attest to the fact that parents' involvement in their children's education not only contributes both to an improvement in the children's achievements and intellectual skills and to the enhancement of the children's self-image and motivation, but also reduces problems of discipline and absenteeism (Abas, 2007). Fisher and Friedman (2009) emphasized the fact that the more the parent feels that the school trusts her/him and seeks her/his genuine involvement, the more willing s/he is to participate in school life. Abas's study (2007) 
demonstrated that when the principal involves the parents in school life and in educational endeavors, the latter are more effective, and the school is strengthened. The template is used to format your paper and style the text. All margins, column widths, line spaces, and text fonts are prescribed; please do not alter them. You may note peculiarities. For example, the head margin in this template measures proportionately more than is customary. This measurement and others are deliberate, using specifications that anticipate your paper as one part of the entire journals, and not as an independent document. Please do not revise any of the current designations.

\section{Research Context}

The current research is part of an evaluation research study whose main goal was to evaluate the program for excellent students at the college with which the present authors are affiliated, as it has been implemented over the last decade, since its inception in 2000. In order to evaluate the program, we interviewed, among others, elementary school principals and high school (that is, middle and secondary schools) principals from the Arab sector who had graduates of the program teaching in their schools. During the interviews, the principals were asked to express their opinions of the graduates; if they perceived the graduates to be exemplary teachers, they were asked to describe the characteristics of their exemplary teaching. If this were not the case, the principals were asked to describe the characteristics of exemplary teaching that they considered the teachers to lack, and explain their reasons. It transpired that the principals' responses in both cases reflected how they perceived the exemplary teacher's characteristics in general, rather than only in the context of the program graduates. The principals were also asked to list the factors they deemed liable to inhibit/encourage the realization of these characteristics and to explain why.

\section{Research Questions}

The main research question was:

1) How do school principals from the Arab sector in Israel perceive the characteristics of exemplary Arab teachers?

Besides this question, the present research focused on a second question that arose as a result of the findings indicating that non-Jewish schools suffer from negative discrimination with regard to the allocation of resources, and that there is a serious shortage of physical and pedagogical infrastructures in the Arab education systemfor example, a shortage of classrooms, well-equipped laboratories, and so on (Jabarin \& Agbariya, 2010; The report of the Follow-up Committee for Arab Education Affairs, 2011; Kahan \& Yelinek, 2000). While these and other factors are liable to inhibit the realization of exemplary teachers' characteristics, there may be additional factors that encourage it. Accordingly, the second research question is as follows:

2) Which factors inhibit/encourage the realization of exemplary teachers' characteristics according to the perception of principals from the Arab sector?

\section{Method}

\subsection{Participant}

The research participants consisted of 10 school principals from the Arab sector-two females and eight males. Two were principals of six-year schools $\left(7^{\text {th }}-12^{\text {th }}\right.$ grades $)$, four were principals of middle schools $\left(7^{\text {th }}-9^{\text {th }}\right.$ grades), and four were principals of elementary schools (three from $1^{\text {st }}-6^{\text {th }}$ grades and one from $1^{\text {st }}-8^{\text {th }}$ grades). One of the elementary schools was private and the rest were state schools. The rationale governing the choice of these particular school principals was to cover the entire spectrum of specializations studied by the graduates of the program for excellent students (such as special education, early childhood, Arabic, Hebrew, English, mathematics-physics, biology-chemistry, and computers-mathematics), who were then placed in those schools.

\subsection{Data Collection}

Essentially, the research described in this article was conducted according to the qualitative research paradigm. Hence, the data were collected by means of semi-structured interviews conducted with the research participants. The duration of each interview, which was recorded on digital tape, was about 90 minutes. Immediately afterwards, the process of transcribing the recorded interviews commenced. The interviews were conducted in Arabic. 


\subsection{Data Analysis}

The collected data were analyzed by means of qualitative tools that merged the "top-down” and the "bottom-up" approaches (Chi, 1997; Spradley, 1979; Stake, 1994). We realized that it was possible to analyze the data with a priori categories reflecting the following components of teachers' professional development: 1) didactic and disciplinary knowledge; 2) knowledge of the school culture and organization; and 3) interpersonal communication. The merging of the "top-down" and the "bottom-up" approaches facilitated the processing and refining of the a priori categories until their secondary categories were formed and identified. Table 1 presents the three a priori categories and the final set of sub-categories that emerged ${ }^{2}$. It also presents one selected quotation for each category ${ }^{3}$.

Table 1. The categories used to analyze the data, with quotations to illustrate them.

The Professional Aspect

\footnotetext{
Mastery of disciplinary and didactic knowledge:

Prior academic achievements: "She approached us, and after we saw her certificates, and we're referring to certificates from high school onward-even her achievements in the Bagrut [matriculation] exams and at college, and she was really exemplary"

Mastery of the curricular material: "She's exemplary because not only did she specialize in her teaching subject, but she specialized at such a high level”

Variety of methods of teaching the discipline: "She plans the lesson according to principles and skills by keeping track of the skills. When she finishes a particular skill, she links it to the skill that comes after it"

Classroom management: "I see a change in him from the point of view of discipline. He's leading this issue because they [the pupils] come to us from the elementary school almost without any norms of behavior, and he emphasizes this aspect"

Professional development: "In addition, she is undergoing in-service training for a new math program, and she's training for it with the team"

Professional evaluation:

Supervisory evaluation: "Even in the interviews conducted by the Arabic supervisor, in relation to the rest of the Arabic-teaching graduates, she was the most outstanding of all"

Colleagues' evaluation: "When this teacher arrived and began to work, I started getting positive reactions from the English team about her"

Pupils' evaluation: "I received comments from the pupils in the classes he teaches. And they requested that he teach them next year. They claim that he's a teacher who teaches in a successful way that enables them to understand the material"
}

\section{The Organizational Aspect}

\section{Organizational climate:}

Performing a cardinal function at the school: "The teacher is with us both as a teacher in the middle school and as a teacher in the high school. And in the middle school, she coordinates the English studies"

Involvement in school life: "He is actively involved in most of the informal activities held at the school"

The physical and pedagogical infrastructure: "Since we belong to the Arab sector, we've always got limitations. There are limitations in the context of state-of the-art laboratories as well as in the context of equipment. But even in these conditions, he does the maximum" The principal's attitude toward the exemplary teacher: "She has never been absent from school, and for that I awarded her a certificate of appreciation. At the school, there are nine teachers who have not been absent at all. All nine received certificates of appreciation and a modest gift"

The colleagues' attitude toward the exemplary teacher: "Because she has special qualities, her colleagues envy her. The envy may be of another type. Why her and not someone else?”

\section{The Personality Aspect}

\section{Interpersonal communication:}

Relationship with the parents: "She communicates with both pupils and parents. The home visits—-hardly a year passes without her visiting each pupil's home and his parents at least once a year"

Relationship with colleagues: "It's not enough for the teacher to excel at teaching; it's essential for him to have other abilities and skills besides those required of him when he was a student, for example, relationships with others and teamwork"

Relationship with the pupils: "She relates to her pupils very respectfully"

Personality qualities:

Self-confidence, consistency, etc.: "In her, I particularly see her self-confidence”

Work ethic: "She attends all the teachers' meetings. She has never been absent. To tell the truth, she was only absent for two days when her daughter was hospitalized"

Family issues: “She still hasn’t begun her studies toward a Master’s degree. It’s very possible that family constraints are causing the delay"

\footnotetext{
${ }_{2}^{2}$ In this table, the categories highlighted in a gray refer to factors that encourage/inhibit the realization of exemplary teachers' characteristics.

${ }^{3}$ The quotations presented in this table and later on in the paper were translated literally from Arabic into English by the researchers.
} 
The classification of the data into the above mentioned categories was based on an "analysis unit" consisting of an idea that refers to one of the exemplary teacher's characteristics or to one of the factors that encourages/ inhibits the realization of these characteristics. The "analysis unit" might be a section of a sentence, a whole sentence, several sentences, or even an extract from an interview.

To assess inter-rater reliability, the two researchers (SI and RS) applied this analysis grid to all the data. Prediscussion inter-rater reliability was $75 \%$. All disagreements were discussed until full agreement was reached. The qualitative analysis enabled the researchers to determine the number of principals who referred to each category at least once during the interviews, as well as the total number of times during the interviews that the principals referred to each of the categories. Based on this, the average number of references per principal for each of the categories was calculated.

In addition to revealing exemplary teachers' characteristics, the first research question related to the ranking of those characteristics in accordance with their degree of importance according to the perception of the principals. Following is a description of how the ranking of these characteristics was carried out:

1) The ranking was based both on the total number of principals who referred to each characteristic (i.e. category) ${ }^{4}$ (at least once) and on the average number of references per principal to each of the characteristics.

2) The characteristics were sorted into three levels of importance (high, medium, and low) in accordance with the total number of principals who referred to each of them. Characteristics to which 8 - 10 principals referred were classified at the highest level of importance; characteristics that were referred to by $5-7$ principals were classified at a medium level of importance, and the rest were classified at the lowest level of importance.

3) At each of the levels mentioned above, an "internal ranking” of the characteristics, according to a descending order of importance, was carried out. The internal ranking was based on the average number of references per principal to each characteristic. Since the average numbers were produced following a quantification procedure that was based on a qualitative analysis, some uncertainty with regard to it was to be expected. Taking this into account, the researchers decided to confer an identical ranking on characteristics in which the difference between the average numbers of references per principal was no more than 0.5 .

\section{Findings and Discussion}

Question 1: "How do school principals from the Arab sector in Israel perceive the characteristics of exemplary Arab teachers?”

Table 2 lists the characteristics of exemplary Arab teachers classified into three levels of importance (high, medium, low) according to the principals' perception. Massive involvement in school life-particularly in leading projects and innovative educational initiatives, the ability to manage a class-particularly to cope with discipline problems successfully, the superior mastery of the curricular material, and the use of a variety of methods to teach the discipline-were sorted into the highest level of importance. At the medium level of importance were the principals' perceptions of characteristics associated with the work ethic, relationships with colleagues and pupils, performing a cardinal function in the school (or alternatively, exemplary teachers' hidden potential that qualifies them to perform such a function), and superior prior academic achievements. Characteristics associated with the professional development, and relationship with the parents, as well as the professional evaluation of the supervisor, colleagues, and pupils, were relegated to the lowest level of importance.

Later on, we portray these findings in greater detail and discuss them. Table 2 shows, along with the classification of the characteristics according to their level of importance (high, medium, low), the emergent "internal ranking” within each level according to a descending order of importance, as perceived by the principals ${ }^{5}$.

Within the high level of importance, the characteristics were divided into two orders of importance (see table 2). At the first order of importance is the characteristic that relates to exemplary teachers' massive and noticeable involvement in school life. The following quotation affords an example of one type of such involvement: "She [a special education teacher in a middle school] has a sense of belonging to the school—she takes turns on the duty roster even though she is not on duty."

\footnotetext{
${ }^{4}$ It should be emphasized that this refers to the categories associated with the emergent characteristics of the exemplary teacher.

${ }^{5}$ It should be mentioned that the category referring to the various qualities of the exemplary teacher (for instance, self-confidence, consistency, and so on) has not been included in this table since it relates to a set of qualities mentioned by the principals with no reference to their operational functions.
} 
Table 2. Characteristics of the exemplary teacher as perceived by the principals, the level of importance of each characteristic, the ranking of the characteristics in decreasing order of importance, the number of principals who related to each characteristic (at least once), and the mean number of references per principal to each characteristic.

\begin{tabular}{|c|c|c|c|c|}
\hline $\begin{array}{l}\text { Mean number } \\
\text { of times per } \\
\text { principal }\end{array}$ & $\begin{array}{l}\text { Number of } \\
\text { principals }\end{array}$ & Characteristics of the exemplary teacher & $\begin{array}{c}\text { Ranking } \\
\text { (in a descending order } \\
\text { of importance) }\end{array}$ & $\begin{array}{l}\text { Level of } \\
\text { importance }\end{array}$ \\
\hline 3.6 & 9 & Involvement in school life & \multirow{2}{*}{1} & \multirow{4}{*}{ High } \\
\hline 3.3 & 8 & Classroom management ability & & \\
\hline 2.1 & 9 & Mastery of the curricular material & \multirow[b]{2}{*}{2} & \\
\hline 1.7 & 10 & Uses a variety of methods of teaching the discipline & & \\
\hline 2.7 & 6 & Work ethic & \multirow{4}{*}{3} & \multirow{5}{*}{ Medium } \\
\hline 2.4 & 5 & Has a good relationship with colleagues & & \\
\hline 2.3 & 6 & Has a good relationship with pupils & & \\
\hline 2.2 & 5 & Performs a cardinal function in the school & & \\
\hline 1.4 & 5 & Prior academic achievements & 4 & \\
\hline 2.7 & 3 & Professional development & 5 & \multirow{5}{*}{ Low } \\
\hline 1.3 & 3 & Supervisor's evaluation & \multirow{4}{*}{6} & \\
\hline 1.3 & 4 & Pupils' evaluation & & \\
\hline 1.3 & 3 & Relationship with parents & & \\
\hline 1.0 & 3 & Colleagues' evaluation & & \\
\hline
\end{tabular}

Another example is described in the following quotation: "He [a science teacher in a middle school] comes early in the morning in order to greet the pupils when they arrive at school. And when they return home, he stands next to the buses [which transport the pupils home] in order to ensure order and security."

Another type of involvement in school life that was particularly striking related to the issue of leading projects and innovative educational initiatives within the school, as is evident in the following quotation: "Something unique that she [a Hebrew teacher in an elementary school] did this year and that she started last year was a kind of project. She prepared a Hebrew-Arabic dictionary for the pupils. This doesn't mean a regular dictionary, but rather something that gives the pupil practice in using a dictionary correctly. This booklet that she wrote trains the pupil to use a dictionary at the various stages. She starts using it in the third and fourth grades, and when the pupil reaches the fifth and sixth grades, he'll already be skilled in retrieving any word from the dictionary in seconds. That was missing in our Arab schools. Seventh- and eighth-grade pupils simply have a hard time looking up [words] in the dictionary."

Another example can be found in the following quotation: "She [a math teacher in a primary school] leads the entire information technology process at the school."

To the best of our knowledge, previous studies on exemplary teachers' characteristics did not relate to involvement in school life as one of their prominent characteristics. Involvement in school life constitutes one of the aspects that characterize a school in which there is an open organizational climate. Thus, based on this finding, it can be concluded that ostensibly the prevailing climate at the schools of the research group (i.e. the schools headed by the research participants) was open. Yet, this is merely according to the impression given by the principals. Hence, this assertion is problematic, since the examination of the organizational climate of the school should be done mainly by investigating the teaching staff. Moreover, this assertion contradicts the present research findings that will be described later on as well as the findings of previous studies indicating that the school culture and organization in most of the schools in the Arab sector are characterized mainly by a closed organizational climate (Ilaiyan, 2000; Ilaiyan \& Toren, 2006; Ilaiyan et al., 2007).

This contradiction can be resolved as follows: For the exemplary teachers (those to which the principals referred during their interviews), the closed organizational climate that characterizes the schools whose principals 
took part in the research does not constitute a factor that inhibits the realization of the characteristic of involvement in school life. This explanation is indicative of an additional layer of excellence in teaching: Exemplary teachers have the potential to realize the characteristics of their exemplary teaching in every situation, irrespective of the existence of various kinds of discouraging factors that are liable to inhibit the realization of these characteristics.

As mentioned previously, one of the noteworthy aspects of involvement in school life referred to leading projects and innovative educational initiatives within the school. One may relate to such activities within the Arab school, which is characterized mainly by a closed organizational climate, as if they were a process of change. This stems from the fact that such a process is anchored in the essence of Western democratic culture, part of which has been rejected by the traditional culture of the school staff and the pupils that characterizes the majority of the schools in the Arab sector (Ilaiyan, 2000; Ilaiyan \& Toren, 2006; Ilaiyan et al., 2007). When introducing a change in such a traditional culture exemplary teachers may well be faced with serious conflicts (Ilaiyan et al., 2007) that are liable to prevent them from successfully bringing about such changes within the school. Yet, in spite of these conflicts, the exemplary Arab teachers have shown themselves to be capable of successfully leading innovative educational initiatives in their schools (as can be understood from what the principals said). Based on this, we suggest relating to exemplary teachers as agents of change who operate according to the "bottom-up" model, that is, the model in which the source of the change initiative is internal-it develops within the school and not outside of it (Fullan, 1991; Gavish, 2004). In this fashion, exemplary teachers serve as central figures in the process of introducing change; they reinforce the change and lead it toward successful implementation (Sharan, 1987; Sharan \& Sharan, 1991).

The principals perceived the ability to manage a class, and particularly to cope with discipline problems successfully, as one of the outstanding characteristics of exemplary teachers, and ranked it, too, at the first order of importance (see Table 2). For instance: "She [a math teacher in a six-year school] has an excellent class [an eighth-grade class of which she was the homeroom teacher], but it has many discipline problems. And we say that in spite of this, she copes with many such problems alone."

This finding upholds research findings reporting that the principals from the Arab sector support charismatic teachers who maintain a proper level of discipline (Eilam, 2002; Toren \& Ilaiyan, 2008). In addition, it is consistent with the findings of previous studies indicating that the ability to cope with discipline problems in the classroom constitutes one of the outstanding characteristics of exemplary teachers (Good \& Brophy, 1990; Manross \& Templeton, 1997). One could surmise that the finding that the principals conferred such a high order of importance on this characteristic is attributable to the fact that the phenomenon of discipline problems has recently become one of the most widespread and irksome phenomena for principals in schools in general (Brock \& Grady, 1997; Hebert \& Worthy, 2001; Loughran, Brown, \& Doecke, 2001) and in schools in the Arab sector in particular (Toren \& Ilaiyan, 2008).

At the second order of importance (within the highest level of importance-see Table 2) was the principals' perception of the characteristic relating to a superior mastery of the curricular material. For instance: "In our school, there are math groups in the eighth grade, ranging from the excellent [pupils] to the weak ones. There are four such groups. She [a math teacher in a middle school] is very competent and has a good mastery of the material."

This supports the findings of numerous studies in the field, reporting that total mastery of the subject matter constitutes one of the prominent characteristics of exemplary teachers (Gilat et al., 2006; Hativa \& Raviv, 1993; Holt-Reynolds, 1999; Sela, 2003; Shulman, 1987, 1989). Similarly, it supports previous research findings reporting that in schools in the Arab sector, in accordance with their organizational culture, a great deal of importance is attributed to a mastery of the discipline (Ilaiyan \& Toren, 2006).

In addition, the characteristic relating to the use of a variety of methods of teaching the discipline can also be found at the second order of importance (see Table 2). The following quotation illustrates this characteristic: "She [a computer and math teacher in an elementary school] integrates information technology into her methods of teaching. She began to build a website involving a variety of worksheets and tests. She takes the pupils to the computer room where she applies all of this."

Another example that relates to the variety of teaching methods can be found in the following quotation: "She [an English teacher in a six-year school] diversifies a great deal. I've seen her doing group work in many lessons, for instance - something that doesn't exist among many other teachers."

This finding is consistent with the many other research findings reporting that the use of a variety of teaching 
methods constitutes one of the outstanding characteristics of exemplary teachers (Good \& Brophy, 1990; Holt-Reynolds, 1999; Sela, 2003; Shulman, 1987, 1989; Tobin \& Fraser, 1987). It should be mentioned that the last quotation is indicative of the possibility that, as opposed to exemplary teachers, a substantial proportion of the teachers in the Arab schools do not employ a variety of methods to teach the discipline. This corroborates the findings of a previous study indicating that veteran teachers in the teachers' room in the Arab sector prefer to use the traditional teaching methods and do not look kindly upon teachers who vary their teaching methods (Ilaiyan, 2000).

A perusal of Table 2 reveals that within the medium level of importance, the characteristics were split into two orders of importance - the third order and the fourth order (see Table 2). At the third order of importance, the following characteristics can be found: work ethic, a good relationship with colleagues and pupils, and performing a cardinal function at the school. The characteristic of "work ethic" has two facets. One facet relates to the exemplary teachers as highly commited as it is described in the following quotation: "Yes, she [a science teacher in an elementary school] is highly committed. She arrives at all the lessons on time and is almost never absent."

The second facet relates to the exemplary teacher's responsibility as it can be found in the following quotation: "He [a science teacher in a middle school] has a great deal of responsibility. He gives over and above his lessons, even after the end of the work day."

To the best of our knowledge, previous studies in the field have barely related to this characteristic as it is reflected in the present study. Studies that did relate to the ethical aspect as one of the characteristics of exemplary teachers did so in the context of the commitment to and ethic of educating all pupils toward the acquisition of "effective” learning (Hativa, 2003a).

The characteristic that relates to good relations with fellow teachers is described in the following quotation: "She [a special education teacher in a middle school] has social excellence. She has the ability to communicate well with the teaching staff, and she has a good relationship with them."

The finding that the principals perceived this characteristic as belonging to the third order of importance contradicts the findings of previous studies (Sela, 2003), which reported that principals attributed a great deal of importance to the establishment of good relations with fellow teachers. It can be understood from this finding that the research participants' schools were apparently characterized by a closed organizational climate, as reported in previous studies (Ilaiyan, 2000; Ilaiyan et al., 2007). The finding further indicates the possibility that the Arab school principals perceived the organizational climate in the school to be closed. It was this perception that guided the principals in the process of shaping the character of the organizational climate that prevailed at their schools.

The research also reveals that the characteristic associated with establishing good relations with the pupils (for example, the teacher mentioned in the previous quotation) can be found at the third order of importance: "Her relationship with the pupils is special, and it can even be said that because she's young, she exploits this relationship positively."

In contrast to previous studies that attributed a great deal of importance to this characteristic (Collinson et al., 1999; Lowman, 1995, 1996; McBer, 2000; Milner et al., 1987; Shulman, 1989), the present study shows that the principals from the Arab sector did not ascribe much importance to it. Once again, this finding demonstrates that a closed organizational climate prevailed at the research participants' schools, as reported in previous studies (Ilaiyan, 2000; Ilaiyan \& Toren, 2006; Ilaiyan et al., 2007).

This finding may also shed light on the epistemological beliefs of the principals from the Arab sector. Based on the fact that the establishment of good relations with the pupils enables the teacher to create a classroom atmosphere that promotes learning (Hativa, 2003b), it can be understood from this finding that the principals did not attribute sufficient importance to the creation of a classroom atmosphere that supports the knowledge construction processes carried out by the pupil himself. Hence, it can be assumed that these principals believed that knowledge must emanate from an authority figure, meaning that the pupil played almost no central role in the process of knowledge construction. This conclusion is consistent with the findings of previous studies (Safadi \& Yerushalmi, 2009), who also pointed to similar epistemological beliefs that are prevalent at schools in the Arab sector.

The characteristic of performing a cardinal function at the school was also ranked at the third order of importance. (For instance: "I' $m$ counting on him to become a member of the management team or of the leading team in the school in the future". Subsequently, the same principal pointed out that he had appointed the teacher re- 
ferred to above as a level coordinator). To the best of our knowledge, previous studies have not related to this characteristic at all.

The characteristics associated with the professional aspect of the exemplary teacher were ranked at lower orders of importance: 1) prior academic achievements ("It is inappropriate for someone to express his objection [namely, his objection to the extent of the early childhood Arabic teacher's expertise and to the extent of her mastery of the material she teaches], and what proves this is her prior achievements and all the diplomas that proved it"); 2) professional development ("He [a science teacher in a middle school] is a diligent teacher who attends all the in-service courses all the time"); and 3) professional evaluation by the supervisor: "Up until this moment, only positive things have been said about her [a computer and math teacher in an elementary school] both by the teaching staff and by the regional advisors who visit from out of town on behalf of the Ministry of Education in connection with the topic of information technology, and everyone says one thing-you have a teacher who is an asset. And she really is."

Exemplary teachers are also evaluated by the pupils-for example: "I hear rumors from the pupils that they're very satisfied with her [a science teacher in an elementary school]", and by colleagues-for example, regarding the same teacher referred to in the previous quotation: "Even her colleagues, the teachers she works with, are very satisfied with her".

Previous studies referred to the characteristic of prior academic achievements as if it were some kind of prerequisite for exemplary teachers (Berliner, 1986; Darling-Hammond, 2000; Fetler, 1999). The characteristic associated with ongoing professional development was reported in previous studies as one of the characteristics of exemplary teachers (Collinson, 1996) and as one of the essential components for teachers' professional development (Vonk, 1995). To the best of our knowledge, those studies have not related to characteristics associated with professional evaluation by the supervisor and by colleagues, or the pupils' evaluation. Despite the fact that these characteristics have come to the fore in the present study, the principals ranked them at a relatively low orders of importance.

The principals perceived exemplary teachers' relationships with the parents ("She [an Arabic teacher in an elementary school] maintains a good relationship with the parents in order to deal with the pupils' problems, and she doesn't stop dealing with the pupils' problems under any circumstances") as a characteristic that was attributed only a low order of importance. We believe this finding to provide additional evidence of the fact that a closed organizational climate prevailed at the research participants' schools. It may be assumed that the principals who were interviewed were not aware of the importance of the parents' involvement in the school or of its positive contribution to the school (Abas, 2007).

Question 2: "Which factors inhibit/encourage the realization of exemplary teachers' characteristics as perceived by principals from the Arab sector?"

The research findings indicated four factors that inhibit/encourage the realization of exemplary teachers' characteristics, namely: 1) the physical and pedagogical infrastructure, 2) the principal's attitude toward exemplary teachers, 3) the attitude of exemplary teachers' colleagues toward them, and 4) exemplary teachers' family issues. Table 3 presents the distribution of the principals into the various categories relating to the four factors described above- once as factors that encourage the realization of the characteristics of exemplary teaching, and once as factors that inhibit it. It should be pointed out that there was no need to relate to the number of times the principals referred to each of the four factors since one reference to a particular factor was sufficient to reveal its existence, irrespective of whether it was an encouraging or an inhibiting factor.

As regards the physical and pedagogical infrastructure, six principals thought that this would be likely to encourage exemplary teachers to realize the characteristics of their exemplary teaching - particularly the characteristic associated with mastery of the didactic and disciplinary knowledge, as the following quotation demonstrates: "There are two computer rooms and she [a computer and math teacher in an elementary school] can take the class wherever she wants. There are demonstration tools, she has television, video, DVD, and also CCTV. If she wants to hold the lesson in the computer room, she can, and at that moment, the entire school can watch her lesson via a live broadcast."

In contrast, four of the principals felt that the physical and pedagogical infrastructure was liable to inhibit the realization of exemplary teachers' characteristics, particularly in the context of varying the teaching methods, for example:

"Interviewer: Do the physical conditions here enable her [a science teacher in a first- to eighth-grade elementary school] to get the maximum from her pupils? 
Table 3. Distribution of the principals in the various categories relating to the factors that encourage/inhibit the realization of the exemplary teacher's disciplinary and didactic knowledge.

\begin{tabular}{|c|c|c|c|c|c|c|}
\hline \multicolumn{2}{|c|}{ The Category } & \multicolumn{3}{|c|}{ Organizational level } & \multirow{2}{*}{\multicolumn{2}{|c|}{$\begin{array}{c}\text { Individual level } \\
\text { Family issues with respect to }\end{array}$}} \\
\hline \multirow{2}{*}{\multicolumn{2}{|c|}{ The factor }} & \multirow{2}{*}{$\begin{array}{l}\text { Physical and } \\
\text { pedagogical } \\
\text { Infrastructure }\end{array}$} & \multirow{2}{*}{$\begin{array}{l}\text { Principals } \\
\text { attitude toward the } \\
\text { exemplary teacher }\end{array}$} & \multirow{2}{*}{$\begin{array}{l}\text { Colleagues' } \\
\text { attitude toward the } \\
\text { exemplary teacher }\end{array}$} & & \\
\hline & & & & & $\begin{array}{l}\text { M.Ed./M.A. } \\
\text { studies }\end{array}$ & $\begin{array}{l}\text { Quality of work } \\
\text { at the school }\end{array}$ \\
\hline \multirow{3}{*}{$\begin{array}{l}\text { Number of } \\
\text { Principals }\end{array}$} & Encouraging & 6 & 9 & 2 & - & - \\
\hline & Inhibiting & 4 & - & 5 & 4 & - \\
\hline & No effect & - & - & - & - & 3 \\
\hline
\end{tabular}

Principal: No.

Interviewer: Is there an existing limitation?

Principal: Yes, certainly. First of all, with respect to science we don't have a laboratory at all. She [the teacher] tells me that she can't do experiments with the pupils. She wants to do this and that, and today she promised them that she would do a certain experiment for them, but she can't. Of course this issue limits her. Second of all, when we divide up the pupils, she takes her group and doesn't stay here in the building. There aren't any rooms here. She goes to the building further down where there is a small office which is a kind of storage-room that's like a basement, and that's where she teaches. Those are the conditions."

This quotation describes a very serious situation at one of the schools in the Arab sector that suffers from extremely difficult physical conditions as well as from a lack of laboratories. Approximately half of the principals interviewed mentioned that their schools suffered from similar conditions. These findings validate the report of the Follow-up Committee for Arab Education Affairs (2011) as well as the study of Jabarin and Agbariya (2010) and the data provided by the Central Bureau of Statistics.

With regard to the principals' attitude toward exemplary teachers, nine principals reported that they supported such teachers, and this attitude constituted a factor that might encourage those teachers to realize the characteristics of their exemplary teaching. For example: "The book she wrote [this refers to the Hebrew-Arabic dictionary mentioned previously] is very organized, and I promised her that after using it for a year or two, we would help her get it published as a book that can be distributed. The book is very user-friendly and can be used by means of worksheets and in stages."

From this quotation, it can be understood that the principal's support for the exemplary teacher might well have been one of the factors that helped her lead projects and innovative initiatives in the school, in spite of the traditional culture that characterizes teachers and pupils alike. In addition, the quotation shows that the principals from the Arab sector supported charismatic teachers who had excellent mastery of the material (Eilam, 2002; Ilaiyan \& Toren, 2000).

With regard to the colleagues' attitude toward exemplary teachers, Table 3 shows that half of the participating principals reported some of the fellow teachers to be envious of exemplary teachers. They believed that this was liable to inhibit the fulfillment of the latter's natural potential, as can be understood from the following quotation, which refers to an English teacher in a middle school:

"Interviewer: Do her fellow teachers accept her as an exemplary teacher?

Principal: There is no doubt that this is a sensitive point, and as the principal, I sense it. I was a member of the staff all the time. I was the vice-principal and always on the administrative team. It's a sensitive point because she was the last one to join the English team, and today she is the English coordinator. This isn't simple, and there are sensitive issues among her fellow teachers-she was the last in and suddenly she's the subject coordinator. This isn't simple. Sometimes I try to help her either overtly or secretly.

Interviewer: How do you do that?

Principal: By talking to her colleagues. I explain that coordinating English is not a kind of monopoly that's earmarked for a specific person. Today she's the coordinator, but tomorrow another teacher may hold that position. Today, you have to help her so that she succeeds, so that in the future she in turn will help whoever the subject coordinator is, otherwise she'll fail. I feel that this helps in a satisfactory way."

The issue of envy among the colleagues of the exemplary teachers who were keen to prove themselves came to the fore when the latter implemented new teaching methods and led educational initiatives. This caused the 
colleagues, especially the veteran ones, to adopt cold, hostile, and alienating attitudes toward the exemplary teachers. It should be mentioned that such attitudes, which have been discussed in previous studies (Eilam, 2002; Ilaiyan et al., 2007), constitute an integral part of the school culture in the Arab sector.

On the other hand, Table 3 demonstrates that two of the principals reported a respectful attitude toward exemplary teachers on the part of their colleagues, as can be detected from the following quotation:

"Interviewer: How do her colleagues relate to her [a Hebrew teacher in an elementary school]?

Principal: In my case, it's well known that a teacher who gives also receives. Most of the teachers at my school are good. I'm speaking in general terms here. I appointed her as the Hebrew coordinator, and there's a teacher who came after her. In other words, she's the first Hebrew teacher to be absorbed into the school. I should point out that our school is still new, and for that reason, there's no sensitivity about the matter."

When questioned about family issues, three of the principals believed that the exemplary teachers' work at the school was not affected by such issues, as can be understood from the following response: "As to her [a math teacher in a middle school] family status, she's married with two children. Taking into account her family status, despite the fact that she has small children, she hasn't been absent once since the beginning of the year. That's very rare among the teachers."

The above quotation shows that the principal related to the exemplary teacher as the exception that proves the rule. Thus, this principal felt that family issues affected the quality of the teachers' work, with the exception of the unusual case of the exemplary teacher mentioned above. In contrast, four of the principals surmised that family issues were liable to inhibit exemplary teachers' ongoing professional development, particularly in the context of studying toward a Master's degree: "She [a special education teacher in a middle school] still hasn't begun her studies toward a Master's degree. It's very possible that family constraints are causing the delay. She just got married a short time ago and I reckon that there are economic reasons [preventing her from studying toward a Master's degree] and nothing more. I imagine that she'll continue [with her studies], and she has the potential to do so."

In most cases, economic reasons and child-rearing were deemed the mother's lot, posing an obstacle that prevented her from investing in extra-familial domains such as advanced academic studies and in-service courses for professional development.

\section{Summary and Conclusion}

The present study examined the manner in which school principals from the Arab sector in Israel perceived the characteristics of exemplary Arab teachers. It also investigated the factors that inhibit/encourage the realization of these characteristics as perceived by the principals.

The emergent characteristics were classified into three levels of importance (high, medium, low), and within each level they were also ranked according to a descending order of importance, as perceived by the principals. The participating principals considered leading educational initiatives, coping with discipline problems, subject matter mastery, and employing a variety of teaching methods to be the exemplary teacher's outstanding characteristics. Characteristics associated with ongoing professional development and relationships with colleagues, pupils, and parents were deemed less prominent.

These findings, alongside the results of previous studies indicating that the school climate in most of the Arab schools in Israel is closed, suggest that the principals related to exemplary teachers as agents of change who led innovative educational initiatives that originated from within the school rather than from outside it (Fullan, 1991; Gavish, 2004). The current findings also suggest that the principals related to exemplary teachers as teachers who are able to apply their characteristics of exemplary teaching - in particular the superior mastery of the curricular material and the use of a variety of methods to teach the discipline - to every situation, despite the existence of factors that are liable to inhibit or prevent their implementation.

With regard to the characteristic relating to exemplary teachers' ability to cope with discipline problems successfully, the finding that the principals conferred such a high order of importance on this characteristic is attributable to the fact that the phenomenon of discipline problems has recently become one of the most widespread and irksome phenomena for principals in schools, as indicated in previous studies (Brock \& Grady, 1997; Hebert \& Worthy, 2001; Loughran, Brown, \& Doecke, 2001; Toren \& Ilaiyan, 2008).

In addition, the research findings might indicate that the principals' perceptions of the characteristics of their schools' organizational climate largely reflected those of a closed organizational climate. Since the principals of 
Arab schools represent a quasi-supreme authority at their schools (Abas, 2007), it can be assumed that they are the ones who determine the nature of their schools' organizational climate. However, the way they do this derives from their perceptions of the characteristics of this climate. Thus, in order to effect a change in the closed organizational climate that prevails at the majority of schools in the Arab sector, a change must first be effected in the principals' perceptions of the characteristics of this climate so that they are consistent with those of an open organizational climate.

With regard to the factors that encourage or inhibit the realization of the characteristics of exemplary teaching, the present study reveals the absence of a unified stance among the principals concerning either the physical and didactic infrastructure or colleagues' attitude toward exemplary teachers. Conversely, there was concurrence among the research participants that the principals' attitude toward exemplary teachers constituted a factor that might encourage the realization of the characteristics of exemplary teaching. As concerns family issues, the findings indicate that there was agreement among the participants that while these issues do not affect the quality of exemplary teachers' work at the school, they are liable to inhibit their ongoing professional development, particularly in the context of their studies toward more advanced degrees.

All in all, it is possible to advise the decision makers in teacher education institutions in general and in Arab teacher education institutions in particular, including those responsible for the excellent student programs, that in parallel to placing the emphasis on studying the corpora of disciplinary and didactic knowledge, special emphasis should be placed on fostering the characteristic of involvement in school life, particularly in the context of leading projects and innovative educational initiatives. In addition, emphasis should be placed on promoting the characteristic related to the ability to manage a classroom-in particular the ability to cope with discipline problems. Despite the fact that the principals attributed a low level of importance to characteristics such as establishing a good relationship with colleagues, pupils, and parents, we also recommend highlighting such characteristics since they are essential for the normal functioning of a teacher within a school setting that is characterized by an open organizational climate. As far as principals from the Arab sector in Israel per se are concerned, we recommend holding special in-service courses for the main purpose of effecting a change in their perceptions of the nature and characteristics of an open organizational climate.

\section{Acknowledgements}

We wish to thank the principals who gave their valuable time to participate in this study. We appreciate the support of "The Academic Arab College for Education in Israel".

\section{References}

Abas, R. (2007). The Role of the Druze School System in Shaping Its Pupils’ Personalities, Identities, and Level of Citizenship: Ethnographic Case Study in Two Druze High Schools. Ph.D. Dissertation, Ramat Gan: Bar Ilan University.

Amir, N., \& Tamir, T. (1992). A Project for Absorbing Novice Teachers_Evaluation Report for 1990-1991. Tel Aviv: Kibbutzim College of Education.

Ben-Peretz, M. (1990). The Teacher-Curriculum Encounter: Freeing Teachers from the Tyranny of Texts. Albany, NY: SUNY Press.

Berliner, D. C. (1986). In Pursuit of the Expert Pedagogue. Educational Researcher, 15, 5-13. http://dx.doi.org/10.3102/0013189X015007007

Bloom, B. S. (1956). Taxonomy of Educational Objectives. Handbook I: Cognitive Domain. New York, NY: D. McKay Co.

Brock, B., \& Grady, M. (1997). From First-Year to First-Rate: Principals Guiding Beginning Teachers. Thousand Oaks, CA: Corwin Press.

Brophy, J. E., \& Good, T. L. (1986). Teacher Behavior and Student Achievement. In M. C. Wittrock (Ed.), Handbook of Research on Teaching (3rd ed., pp. 376-391). New York, NY: Macmillan.

Bruner, J. (1960). The Process of Education. New York, NY: Vintage.

Chi, M. T. H. (1997). Quantifying Qualitative Analyses of Verbal Data: A Practical Guide. The Journal of the Learning Sciences, 6, 271-315. http://dx.doi.org/10.1207/s15327809jls0603_1

Chubbuck, S. M., Clift, R. T., Allard, J., \& Quinlan, J. (2001). Playing It Safe as a Novice Teacher: Implications for Programs for New Teachers. Journal of Teacher Education, 52, 365-376. http://dx.doi.org/10.1177/0022487101052005003

Collinson, V. (1996). Becoming an Exemplary Teacher: Integrating Professional, Interpersonal, and Intrapersonal Knowledge. Paper Presented at the Annual Meeting of the Japan-United States Teacher Education Consortium, Naruto, 15-18 
July 1996.

Collinson, V., Killeavy, M., \& Stephenson, H. J. (1999). Exemplary Teachers: Practicing an Ethic of Care in England, Ireland and the United States. Journal for a Just and Caring Education, 5, 349-366.

Cruickshank, D. R., \& Haefele, D. (2001). Good Teachers, Plural. Educational Leadership, 58, 26-30.

Darling-Hammond, L. (2000). Teacher Quality and Students' Achievement: A Review of State Policy Evidence. Education Policy Analysis Archives (EPAA), 8. http://epaa.asu.edu/ http://dx.doi.org/10.14507/epaa.v8n1.2000

Eilam, B. (2002). Passing through a Western-Democratic Teacher Education: The Case of Israeli-Arab Teachers. Teacher College Record, 104, 1656-1701. http://dx.doi.org/10.1111/1467-9620.00216

Erlich, Y. (1992). The Accompaniment in Absorption during the 1991 Academic Year. Dapim, 14, 85-87.

Fetler, M. (1999). High School Staff Characteristics and Mathematics Test Results. Educational Policy Analysis Archives, 7. http://dx.doi.org/10.14507/epaa.v7n9.1999

Fisher, Y., \& Friedman, Y. (2009). The Parents and the School: Interrelationships and Involvement. Dapim, 47, 11-40.

Follow-Up Committee for Arab Education Affairs (2011). Central Issues, Needs, and Deprivations in Arab Education in Israel.

Friedman, R. (2002). The Effect of the Guidance Approach of the Home-Room Teacher on the Self and Professional Image of the Student in the Induction Process. Paper Submitted in Partial Fulfillment of the Requirements for a Master's Degree in the Education Department of Bar Ilan University, Ramat Gan: Bar Ilan University.

Friedman, Y., Horovitz, T., \& Shliv, R. (1988). The Effectiveness of Schools' Culture and Climate. Jerusalem: The Henrietta Szold Institute.

Fullan, M. (1991). The New Meaning of Educational Change. Toronto: Teachers College Press.

Gavish, V. (2004). The Relationship between External Agents of Change and Internal Agents of Change in Schools Undergoing a Process of Change. In S. Guri-Rosenblitt (Ed.), Teachers in a World of Change (pp. 97-131). Raanana: The Open University.

Gilat, Y., Bar-On, S., Genis, A., Gad, D., \& Bachar, E. (2006). Effective Teaching in a College of Education: The Viewpoint of Students and of Teacher Educators. Dapim, 43, 39-59.

Good, T. L., \& Brophy, J. E. (1990). Teacher Behavior and Student Achievement. In M. C. Wittrock (Ed.), Handbook of Research on Teaching (3rd ed., pp. 328-375). New York: MacMillan.

Goodlad, J. (1984). A Place Called School: Prospects for the Future. New York: McGraw-Hill.

Green, A. (2010). Can Good Teaching Be Learned? Hed Hahinuch, 85, 70-73.

Hativa, N. (2000). Becoming a Better Teacher: A Case of Changing the Pedagogical Knowledge and Beliefs of Law Professors. Instructional Science, 28, 491-523. http://dx.doi.org/10.1023/A:1026521725494

Hativa, N. (2003a). Teaching Processes in the Classroom. Tel Aviv: Academic Publishing for Developing Teaching Staff.

Hativa, N. (2003b). Is There a “Gimmick” for Achieving Excellence in Teaching? Al Hagova, 2, 12-16.

Hativa, N. (2010). How Is Good Teaching Taught? Hed Hahinuch, 85, 76-78.

Hativa, N., \& Marincovich, M. (Eds.) (1995). Disciplinary Differences in Teaching and Learning Implications for Practice: New Directions for Teaching and Learning, Number 64. San Francisco, CA: Jossey-Bass Inc.

Hativa, N., \& Raviv, A. (1993). Using a Single Score for Summative Teacher Evaluation by Students. Research in Higher Education, 34, 625-646. http://dx.doi.org/10.1007/BF00991923

Hativa, N., Barak, R., \& Simhi, E. (2001). Expert University Teachers: Thinking, Knowledge and Practice Regarding Effective Teaching Behaviors. The Journal of Higher Education, 72, 699-729. http://dx.doi.org/10.2307/2672900

Hebert, E., \& Worthy, T. (2001). Does the First Year of Teaching Have to Be a Bad One? A Case Study of Success. Teaching and Teacher Education, 17, 897-911. http://dx.doi.org/10.1016/S0742-051X(01)00039-7

Hertz-Lazarovich, R. (1984). Learning in an Active Class-The Desired and the Existing. A Guide for the Teacher. Jerusalem: Ministry of Education and Culture, The Center for Curricular Center.

Hines, C., Cruickshank, D. R., \& Kennedy, J. J. (1985). Teacher Clarity and Its Relationship to Student Achievement and Satisfaction. American Educational Research Journal, 22, 87-99. http://dx.doi.org/10.3102/00028312022001087

Hofstein, A., \& Tamir, P. (1984). Evaluation of Teaching in the Science Classroom. In Evaluation in Science Education (Chap. 4, pp. 71-94). Jerusalem: Department of Science Teaching, The Weizmann Institute of Science \& Israel Science Teaching Center, The Hebrew University.

Holt-Reynolds, D. (1999). Good Readers, Good Teachers? Subject Matter Expertise as a Challenge in Learning to Teach. Harvard Educational Review, 69, 29-50. http://dx.doi.org/10.17763/haer.69.1.pl5m5083286l77t2 
Ilaiyan, S. (2000). Secondary School Dropout from the Minority Sector in Israel. PhD Thesis, Budapest: PhD School of Education, Faculty of Arts, Eotvos Lorand University.

Ilaiyan, S., \& Toren, Z. (2006). The Time Dimension in the Practicum: Students' Perception of the Efficacy of Two Types of Practicum. Dapim, 41, 197-222.

Ilaiyan, S., Zaidan, R., \& Toren, Z. (2007). The Motives for Choosing the Teaching Profession among Student Teachers in the Arab Sector. Dapim, 44, 123-147.

Jabarin, Y., \& Agabariya, A. (2010). Education on Hold: Government Policy Regarding Civil Initiatives for Promoting Arab Education in Israel. Nazareth: Dirasat.

Kahan, S., \& Yelinek, Y. (2000). Discrimination against the Non-Jewish Sector in the Allocation of Care Resources in Education: Its Quantitative Measurement and Implications for Its Cancellation (Hence-Kahan-Yelinek/The Report). Jerusalem: School of Education, The Hebrew University.

Leinhardt, G. (1986). Expertise in Mathematics Teaching. Educational Leadership, 43, 28-33.

Loughran, J., Brown, J., \& Doecke, B. (2001). Continuities and Discontinuities: The Transition from Pre-Service to FirstYear Teaching. Teachers and Teaching: Theory into Practice, 7, 7-23. http://dx.doi.org/10.1080/13540600125107

Lowman, J. (1995). Mastering the Techniques of Teaching (2nd ed.). San Francisco, CA: Jossey-Bass.

Lowman, J. (1996). Characteristics of Exemplary Teachers. New Directions for Teaching and Learning, 65, 33-40. http://dx.doi.org/10.1002/tl.37219966508

Manross, D., \& Templeton, C. (1997). Expertise in Teaching Physical Education. Recreation and Dance, 68, 29-35. http://dx.doi.org/10.1080/07303084.1997.10604908

McBer, H. (2000). Research into Teacher Effectiveness: A Model of Teacher Effectiveness. Nottingham: Department for Education and Employment.

Millet, S. (1986). Exposing Curricular Knowledge Imparted to Teachers in Workshops for Curriculum Development. M.A. Thesis, Tel Aviv: Tel Aviv University.

Millet, S. (2001). “It’s an Eternal Race in Which I Have to Advance and Progress All the Time...”: Changes in the Development of Novice Teachers' "Didactic Knowledge” and "Self Knowledge”. Ma'of u-Ma'aseh, 3, 47-78.

Millet, S., (1995). Qualitative Research Tools in Exposing Curricular Knowledge Imparted to Teachers in Workshops for Curriculum Development. Ma'of u-Ma'aseh, 2, 7-20.

Milner, N., Ben-Zvi, R., \& Hofstein, A. (1987). Variables That Affect Students' Enrolment in Science Courses. Research in Science and Technological Education, 5, 201-207. http://dx.doi.org/10.1080/0263514870050210

Safadi, R., \& Yerushalmi, E. (2009). Students’ Perceptions of a Self-Diagnosis Task. In M. Sabella, C. Henderson, \& C. Singh (Eds.), Physics Education Research Conference Part of the PER Conference Series (Vol. 1179, pp. 257-260). Ann Arbor, MI: AIP Publishing. http://dx.doi.org/10.1063/1.3266730

Sagee, R., \& Regev, H. (2002). Difficulties of the Novice Teacher: A Sense of Shock as a Discomfort in Future Teaching. Dapim, 34, 10-43.

Schwab, J. J. (1964). Structure of the Disciplines: Meaning and Significance. In G. W. Ford, \& L. Pugno (Eds.), The Structure of Knowledge and Curriculum (pp. 6-30). Chicago, IL: Rand McNally.

Sela, D. (2003). Characteristics of Excellence among Physics Teachers at a High School and Their Contribution to Improving Teaching. PhD Dissertation, Jerusalem: The Hebrew University.

Sharan, S. (1987). Preparing a Teacher for the 21st Century. Selected Extracts from the Carnegie Report. Hed Hahinuch, 22, $18-20$.

Sharan, S., \& Sharan, Y. (1991). Changing Instructional Methods and the Culture of the School. In N. Wyner (Ed.), Current Perspectives on the Culture of Schools (pp. 143-164). Cambridge, MA: Brookline Books.

Shkedi, A. (2000). Educating Reflective Teachers for Teaching Culturally Valued Subjects: Evaluation of a Teacher-Training Project. Evaluation and Research in Education, 14, 94-110. http://dx.doi.org/10.1080/09500790008666965

Shulman, L. S. (1987). Knowledge and Teaching: Foundations of the New Reform. Harvard Educational Review, 57, 1-22. http://dx.doi.org/10.17763/haer.57.1.j463w79r56455411

Shulman, L. S. (1989). Towards a Pedagogy of Substance. AAHE Bulletin, 41, 8-13.

Spradley, J. (1979). The Ethnographic Interview. New York: Rinehart and Winston.

Stake, R. E. (1994). Case Studies. In N. K. Denzin, \& Y. S. Lincoln (Eds.), Handbook of Qualitative Research (pp. 220-235). Thousand Oaks, CA: Sage.

Talmor, R., Nabal-Heller, N., \& Erlich, A. (1996). The Absorption of Novice Teachers from the School Principal's Point of View. Proceedings of the 2nd International Conference on Teacher Education: "Conservatism, Development and Innova- 
tion”, Israel, 30 June-4 July 1996.

Tamir, P., \& Caridin, H. (1993). Characteristics of the Learning Environment in Biology and Chemistry Classes as Perceived by Jewish and Arab High School Students in Israel. Research in Science and Technological Education, 11, 5-14. http://dx.doi.org/10.1080/0263514930110102

Tobin, K., \& Fraser, B. J. (Eds.) (1987). Exemplary Practice in Science and Mathematics Education. Perth: Curtin University of Technology.

Toren, Z., \& Ilaiyan, S. (2008). The Problems of the Beginning Teacher in the Arab School in Israel. Teaching and Teacher Education, 24, 1041-1056. http://dx.doi.org/10.1016/j.tate.2007.11.009

Vonk, J. H. C. (1995). Conceptualizing Novice Teachers' Professional Development: A Base for Supervisory Interventions. Paper Presented at the Annual Conference of AERA, San Francisco, 18-22 April 1995.

Young, S., \& Shaw, D. G. (1999). Profiles of Effective College and University Teachers. The Journal of Higher Education, 70, 670-687. http://dx.doi.org/10.2307/2649170

Ziv, S., Silberstein, M., \& Tamir, P. (1994). Increasing the Effectiveness of Learning How to Teach in Preservice Education. Interchange, 25, 157-170. http://dx.doi.org/10.1007/BF01534542

Zuzovsky, R. (1998). Teachers’ Knowledge: Exposure and Conceptualization-Advanced Course in Teacher Education. In M. Silberstein, M. Ben-Peretz, \& S. Ziv (Eds.), Reflection in Teaching: Central Pivot/Crossroads in a Teacher's Development (pp. 128-157). Tel Aviv: The MOFET Institute. 